\title{
A Potential Green Medicine from Sri Lanka against the Major Cariogenic Bacterium, Streptococcus mutans
}

\begin{abstract}
Rathnayaka GRAI ${ }^{1}$, Jayatilake JAMS ${ }^{2}$ and Paranagama MP ${ }^{1 *}$
${ }^{1}$ Department of Basic Sciences, Faculty of Dental Sciences, University of Peradeniya, Sri Lanka ${ }^{2}$ Department of Oral Medicine and Periodontology, Faculty of Dental Sciences, University of Peradeniya, Sri Lanka
\end{abstract}

*Corresponding author: MP Paranagama, Department of Basic Sciences, Faculty of Dental Sciences, University of Peradeniya, Peradeniya, Sri Lanka, Tel: 94-81-2397564; Email: madhaviparanagama@gmail.com

\section{Research Article \\ Volume 5 Issue 4}

Received Date: October 15, 2020

Published Date: October 27, 2020

DOI: 10.23880 /oajds- 16000276

\section{Abstract}

Dental caries is the most common infectious disease of mankind. S. mutans is the leading cariogenic bacterium involved in the pathogenesis of dental caries. In Sri Lankan folklore, a traditional betel quid (TBQ) which consists of Piper betle (leaves), Syzygium aromaticum (flower buds), Myristica fragrans (seed and mace), Elettaria cardamomum (fruits), Areca catechu (seeds), Kaempferia galanga (rhizomes) and Coriandrum sativum (seeds) is claimed to protect oral health. Recently, we have scientifically proven its antiperiodontopathic and antigenotoxic effects. In this study, we show the anticariogenic effect of this TBQ through its inhibitory effect on $S$. mutans. In agar well diffusion assay, hexane, ethyl acetate, methanol and water extracts of this TBQ at a concentration of $100 \mathrm{mg} / \mathrm{ml}$ exhibited zones of inhibition with a diameter of $14.5 \pm 2.1,15.5 \pm 3.5,15.5 \pm 2.1$, $13.8 \pm 1.8 \mathrm{~mm}$ respectively. Moreover, its ethyl acetate extract showed dose dependant $S$. mutans inhibitory effects and a MBC of $250 \mu \mathrm{g} / \mathrm{ml}$. These findings indicate the potential of this TBQ to be developed into a green medicine against $S$. mutans and prevent dental caries.

Keywords: Dental caries; S. mutans; Herbal medicines; Preventive Dentistry

Abbreviations: EA: Ethyl Acetate; DMSO: Dimethyl Sulfoxide; TSB: Tryptic Soy Broth; TSA: Tryptic Soy Agar; SD: Standard Deviation; TBQ:Traditional Betel Quid; CFU:Colony Forming Units; MIC: Minimum Inhibitory Concentration; MBC: Minimum Bactericidal Concentration

\section{Introduction}

Dental caries is the single most common oral infection of mankind [1]. The bacterium Streptococcus mutans is considered to be the major pathogenic bacterium involved in causing dental caries [2,3]. Its impact on individuals and communities is reflected as pain and suffering, reduced quality of life and the economic burden due to absence from daily activities and the high cost of dental treatment [4-6]. In addition, $S$. mutans can also enter the circulation and cause endocarditis and stroke $[7,8]$.
Despite the advancements in dental caries detection and prevention, 2.3 billion people are still affected with caries in permanent teeth and more than 530 million children are affected with caries in primary teeth. However, dental caries is a preventable disease. Unfortunately, in most low and middle income countries, still the main focus is treating caries by restoration of the cavities once it is detected, rather than on preventing the occurrence of the disease [9].

One of the major aims in preventing dental caries is reduction of the cariogenic bacterial load in the oral cavity. Fluoride is the most frequently used synthetic compound to prevent dental caries [10]. However, recent research provide evidence for emergence of fluoride resistance among $S$. mutans [11]. Besides, exposure to excess fluoride through ingestion of fluoridated tooth pastes during the period of tooth formation is a persisting concern especially in the areas 
where dental fluorosis is endemic [12]. Various non-fluoride synthetic agents used in prevention of dental caries include chlorhexidine, povidone iodine, cetyl pyridinium chloride, and sodium hypochlorite [13].

Since ancient times, herbal medicines also have been used in prevention of dental caries [14-16]. Even now, many herbal remedies are used in low and middle income countries without proper scientific validation. Indeed, people believe that such traditional herbal remedies have no adverse effects as they come from natural sources. Therefore, it is important to comprehensively analyze the efficacies and toxicities of these traditional remedies and promote their use as alternative treatments or as potential sources of new drugs to be used in prevention of dental caries [17].

One of the time tested herbal remedies claimed to have oral health protective effects in Sri Lankan folklore is a traditional betel quid (TBQ) which consists of leaves of betel (Piper betle), flower buds of clove (Syzygium aromaticum), seeds and mace of nutmeg (Myristica fragrans), fruits of cardamom (Elettaria cardamomum), seeds of arecanut (Areca catechu), rhizomes of java galangal (Kaempferia galanga) and seeds of coriander (Coriandrum sativum). Recently we have reported its antiperiodontopathic and antigenotoxic effects [18]. However, its anticariogenic properties have not been characterized yet.

Hence, the objective of the present study was to analyze the anticariogenic potential of this TBQ by screening its growth inhibitory effects on $S$. mutans using an agar well diffusion assay and determine its MBC on this bacterium using a standard broth micro dilution assay.

\section{Materials and Methods}

\section{Ethical clearance}

Ethical clearance for this study was obtained from the ethics review committee of the Faculty of Dental Sciences, University of Peradeniya (Ethical Clearance Certificate No FDS-FRC/ 2014/16).

\section{Chemicals and Equipment}

The solvents for extraction were purchased from BDH, UK and the bacteriological media were purchased from Oxoid, UK.

\section{Preparation of Extracts}

Collection of plant materials and preparation of the TBQ were done as described elsewhere [18]. It was extracted at a solid: solvent ratio of 1:10 in hexane, ethyl acetate (EA), methanol and water. Extractions in organic solvents were done in a soxhlet apparatus for $2 \mathrm{~h}$ at $30^{\circ} \mathrm{C}$ and the extracts were concentrated under reduced pressure in a rotary evaporator. The water extract was obtained by heating the mixture in distilled water for $2 \mathrm{~h}$ at $70^{\circ} \mathrm{C}$ and lyophilized. The dried extracts were stored at $-20^{\circ} \mathrm{C}$. The organic solvent extracts were reconstituted in dimethyl sulfoxide (DMSO) and the water extract was reconstituted in distilled water. All the reconstituted extracts were filter sterilized using disposable filters with a pore size of $0.2 \mu \mathrm{m}$ before analyses.

\section{Streptococcus mutans Strain and Growth Conditions}

Standard S. mutans culture (ATCC 700610) from American Type Culture Collection, USA was a generous gift from Prof. P. S. Rajapakse. It was revived by culturing in Tryptic Soy Broth (TSB) (Oxoid, UK) at $37^{\circ} \mathrm{C}$ under anaerobic conditions in an anaerobic jar for $48 \mathrm{~h}$. Stock cultures prepared from this broth culture were maintained in $40 \%$ $\mathrm{v} / \mathrm{v}$ glycerol at $-80^{\circ} \mathrm{C}$ throughout the study period.

\section{Agar Well Diffusion Assay}

TBQ extracts were tested for dose dependent antimicrobial effects using agar well diffusion assay as described by Evans, et al. [19]. An overnight broth culture of $S$. mutans was used for the assay. After ensuring a pure growth of organisms using Gram's stain, a $3 \mathrm{ml}$ aliquot $S$. mutans culture was adjusted to 0.5 McFarland turbidity standard $\left(1.5 \times 10^{8} \mathrm{CFU} / \mathrm{ml}\right)$. It was evenly spread on the surface of tryptic soy agar (TSA) plates supplemented with $5 \%$ sheep blood and the excess was removed after 2 min. Thereafter, $9 \mathrm{~mm}$ wells were made on agar plates using a stainless steel borer. Afterwards, the wells were filled with $200 \mu \mathrm{l}$ of the tested extract. Chlorhexidine $(0.2 \%)$ and gentamycin were used as positive controls and 10\% DMSO and sterile distilled water were used as negative controls. After an incubation period of $24 \mathrm{~h}$, bacteria became confluent on the surface of the agar plates except in the areas of growth inhibition around the wells which became evident as clear helos. These zones of inhibition were measured using a micrometer gauge. To assess the dose dependent $S$. mutans growth inhibitory effects, a serial dilution $(100 \mathrm{mg} / \mathrm{ml}, 50 \mathrm{mg} / \mathrm{ml}$ and $25 \mathrm{mg} /$ $\mathrm{ml}$ ) of the EA extract was used.

\section{Determination of the MBC of the TBQ extract on S. mutans}

The MBC was determined by standard microplate broth dilution assay according to CLSI guidelines [20]. Briefly, 2 -fold serial dilutions of the extracts were prepared and added to TSB. The extract was serially diluted to have a final concentration of $62.5 \mu \mathrm{g} / \mathrm{ml}-8 \mathrm{mg} / \mathrm{ml}$ per well. Then an 
inoculum of $10^{5} \mathrm{CFU}$ of the organism were inoculated to each well and incubated as described above. After $24 \mathrm{~h}, 2 \mu \mathrm{l}$ of the culture from each well were spotted on tryptic soy agar supplemented with 5\% sheep blood and incubated for $24 \mathrm{~h}$ under the anaerobic conditions describe above. The lowest concentration of the extract with no bacterial growth on agar plate was taken as the MBC.

\section{Data Analysis}

Data were analyzed using Graph Pad Prism software (version 6, USA). The results are expressed as mean \pm standard deviation (SD) from three independent experiments.

\section{Results}

\section{Growth Inhibitory Effects of the Different Solvent Extracts of the TBQ on S. Mutans}

As shown in Figure 1, EA, methanol, hexane and water extracts of the TBQ at a concentration of $100 \mathrm{mg} / \mathrm{ml}$ showed zones of inhibition with diameters of $17.5 \pm 0.7 \mathrm{~mm}$, $16.0 \pm 1.4 \mathrm{~mm}$ and $15.5 \pm 0.7 \mathrm{~mm}$ and $15.0 \pm 0 \mathrm{~mm}$ respectively. The ZOI was highest for ethyl acetate extract followed by methanol, hexane and water extracts. ZOIs for chlorhexidine (positive control) was $17.8 \pm 0.3 \mathrm{~mm}$ and $10 \%$ DMSO (negative control) was $0 \mathrm{~mm}$.

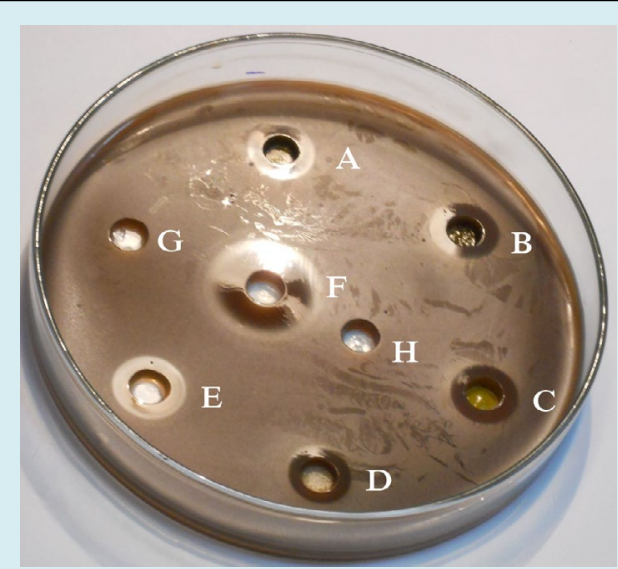

Figure 1: A photograph of a bacterial culture plate showing the $S$. mutans growth inhibitory effects of different solvent extracts of the Sri Lankan TBQ. The well A contains (methanol extract), B (ethyl acetate extract), C (hexane extract), D (water extract), E (0.2\%chlorhexidine), F (Gentamycin), G (10\% DMSO) and H (water).

\section{Dose Dependent Growth Inhibitory Effects of the EA Extract of the TBQ on S. Mutans}

Next we attempted to test the dose dependent growth inhibitory effects of the EA extract of this TBQ on $S$. mutans by employing a serial dilution of the extract $(100 \mathrm{mg} / \mathrm{ml}, 50$ $\mathrm{mg} / \mathrm{ml}$ and $25 \mathrm{mg} / \mathrm{ml}$ ) in agar well diffusion assay. As shown in Figure 2, there was a dose dependent increment in the mean ZOI.

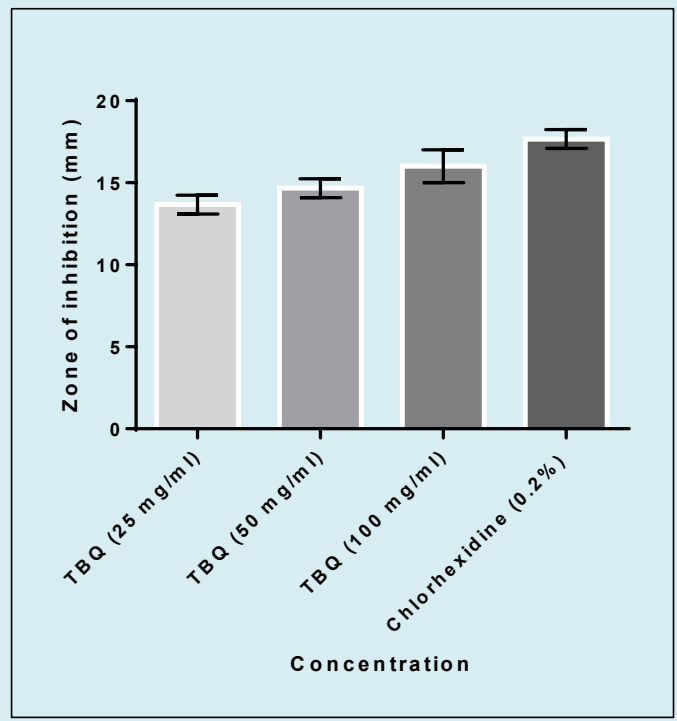

Figure 2: Dose dependent growth inhibitory effects of the EA extract of the Sri Lankan TBQ against $S$. mutans.

\section{Discussion}

Prevention of dental caries is a prime requirement of the entire world. At present there is a huge demand for natural anticariogenic compounds to meet this requirement since a growing body of evidence highlights the side effects of currently used synthetic anticariogenic compounds $[11,12,21,22]$. According to the results of our study, all four extracts of this TBQ (hexane, EA, methanol and water) have natural antibacterial compounds against $S$. mutans. This finding indicates that it is a rich source anti-S. mutans compounds with varying polarities. When we compared the zones of inhibition detected for these four extracts using ANOVA, there was no statistically significant difference among them $(\mathrm{p}<0.05)$ (data not shown). Nonetheless, EA extract showed the highest zone of inhibition. Therefore, the EA extract was used for analyzing the dose dependent antibacterial effects and the MBC. Subsequent tests revealed that the EA extract has dose dependent $S$. mutans inhibitory effects and a MBC of $250 \mu \mathrm{g} / \mathrm{ml}$.

When we compared the antimicrobial potential of the TBQ extract tested in this study with that of its constituent ingredients reported in scientific literature, it was found that this TBQ extract is superior to them. For example, the $\mathrm{MBC}$ of the water extract of piper betle was $0.5 \mathrm{mg} / \mathrm{ml}$ while the MBCs of the ethanol extracts of the seed and mace $M$. 
fragrans were $20 \mathrm{mg} / \mathrm{ml}$ and $40 \mathrm{mg} / \mathrm{ml}$, respectively [23,24]. A methanol extract of $S$. aromaticum flower buds was reported to have a $\mathrm{MBC}>2.5 \mathrm{mg} / \mathrm{ml}$ [25]. According to Aneja and Radhika, the MBC of organic solvent extracts (ethanol, methanol and acetone) of E. cardamomum fruit was $5 \mathrm{mg} /$ $\mathrm{ml}$ [26]. A methanol extract of $A$. catechu seeds has shown a MIC of $100 \mu \mathrm{g} / \mathrm{ml}$, but its MBC was not reported so far [27]. The MIC and MBC of $C$. sativum seeds also have not been reported in the scientific literature. However, essential oils extracted from C. sativum leaves have shown a MBC of 62.5$125 \mu \mathrm{g} / \mathrm{ml}$, which is comparable to the MBC obtained for the TBQ in our study [28]. The preliminary screening of TBQ ingredients in our laboratory for $S$. mutans inhibitory effects by agar well diffusion assay showed a ZOI of $16.5 \pm 0.7 \mathrm{~mm}$ for the EA extract of $C$. sativum seeds (data not shown). A study conducted by Hertiani, et al. has shown that ethanol extract of $K$. galanga has a MBC at $2.724 \% \mathrm{w} / \mathrm{v}$ [29].

Further studies are in progress to analyze the effect of this TBQ extract on clinical isolates of the organism and also on oral biofilm formation and expression of virulent genes in S. mutans.

\section{Conclusion}

The Sri Lankan TBQ tested in this study contains antibacterial compounds against $S$. mutans, the major cariogenic pathogen. This is the first study to report the anticariogenic potential of this TBQ. Although the anti-S. mutans activities of the individual ingredients of this TBQ have been reported earlier, we show that the combination of these ingredients in the traditional TBQ has a better $S$. mutans inhibitory effect. In light of the rapid spread of antibiotic resistance throughout the world and accumulating evidence on adverse effects of chemical oral hygienic products, natural antimicrobial agents in this Sri Lankan TBQ may have the potential for further development into feasible and economical green medicines in prevention and treatment of dental caries.

\section{Acknowledgements}

Authors wish to thank the University of Peradeniya for the financial support (research grant RG/AF/2013 D), Prof. P. S. Rajapakse, Department of Oral medicine and Periodontology, Faculty of Dental Sicences for providing the standard S. mutans culture, Dr A.L.S. Dharmaparakrama, Betel Research Institute, Narammala for provision of betel, Dr Palika, Fernando, Veterinary Research Institute, Gannoruwa for provision of sheep blood, Mr. M. G. B. Gangadhara and Ajith Rathnakumara, Department of Basic Sciences, Faculty of Dental Sciences, for their support in laboratory work.

\section{References}

1. Frencken JE, Sharma P, Stenhouse L, Green D, Laverty D, et al. (2017) Global epidemiology of dental caries and severe periodontitis-a comprehensive review. J Clin Periodontol 44(18): 94-105.

2. Selwitz RH, Ismail AI, Pitts NB (2007) Dental caries. The Lancet 369(9555): 51-59.

3. Loesche WJ (1986) Role of Streptococcus mutans in human dental decay. Microbiol Rev 50(4): 353-380.

4. Lamster IB (2018) 2017 FDI policy statements. Int Dent J 68(1): 3.

5. Kassebaum NJ, Smith AGC, Bernabe E, Fleming TD, Reynolds AE, et al. (2017) Global, Regional, and National Prevalence, Incidence, and Disability-Adjusted Life Years for Oral Conditions for 195 Countries, 1990-2015: A Systematic Analysis for the Global Burden of Diseases, Injuries, and Risk Factors. Journal of Dental Research 96(4): 380-387.

6. Petersen PE (2014) Strengthening of oral health systems: oral health through primary health care. Med Princ Pract 23(1): 3-9.

7. Inenaga C, Hokamura K, Nakano K, Nomura R, Naka S, et al. (2018) A Potential New Risk Factor for Stroke: Streptococcus mutans with Collagen-Binding Protein. World Neurosurg 113: 77-81.

8. Kondo Y, Hoshino T, Ogawa M, Hidaka K, Hasuwa T, et al. (2019) Streptococcus mutans isolated from a 4-year-old girl diagnosed with infective endocarditis. Clinical and Experimental Dental Research 5(5): 534-540.

9. https://www.who.int/news-room/fact-sheets/detail/ oral-health.2020. Accessed on 1st October, 2020

10. Marinho VC, Chong LY, Worthington HV, Walsh T (2016) Fluoride mouthrinses for preventing dental caries in children and adolescents. Cochrane Database Syst Rev 7(7): Cd002284.

11. Liao Y, Brandt BW, Li J, Crielaard W, Van Loveren C, et al. (2017) Fluoride resistance in Streptococcus mutans: a mini review. J Oral Microbiol 9(1): 1344509.

12. Denbesten P, Li W (2011) Chronic fluoride toxicity: dental fluorosis. Monogr Oral Sci 22: 81-96.

13. Wang Y, Li J, Sun W, Li H, Cannon RD, et al. (2017) Effect of non-fluoride agents on the prevention of dental caries in primary dentition: A systematic review. PLoS ONE 


\section{Open Access Journal of Dental Sciences}

12(8): e0182221.

14. Karunarathne HMHL, Gamlath NWGND (2016) Medical Formulas for Krimidanta (Dental Caries) in Indigenous Medicine in Sri Lanka-a Literary Review. International Journal of Ayurveda and Pharma Research 4(9): 52-56.

15. Badria FA, Zidan OA (2004) Natural products for dental caries prevention. J Med Food 7(3): 381-384.

16. Cheng L, Li J, He L, Zhou X (2015) Natural products and caries prevention. Caries Res 49(1): 38-45.

17. WHO Traditional Medicine Strategy 2014-2023 (2013). pp: 1-76.

18. Paranagama MP, Piyarathne NS, Nandasena TL, Jayatilake S, Navaratne A, et al. (2020) The Porphyromonas gingivalis inhibitory effects, antioxidant effects and the safety of a Sri Lankan traditional betel quid-an in vitro study. BMC Complement Med Ther 20(1): 259.

19. Evans A, Leishman S, Walsh L, Seow W (2015) Inhibitory effects of antiseptic mouthrinses on Streptococcus mutans, Streptococcus sanguinis and Lactobacillus acidophilus. Australian Dental Journal 60(2): 247-254.

20. Clinical and Laboratory Standards Institute (2012) Performance Standards for Antimicrobial Susceptibility Testing. Twenty-Second Informational Supplement. CLSI Document M100-S22. Wayne, PA: Clinical and Laboratory Standards Institute.

21. Thomas MS, Denny C (2014) Medication-related tooth discoloration: a review. Dental update 41(5): 440442,445-447.

22. Plantinga NL, Wittekamp BHJ, Leleu K, Depuydt P, Van den Abeele AM, et al. (2016) Oral mucosal adverse events with chlorhexidine $2 \%$ mouthwash in ICU. Intensive Care Med 42(4): 620-621.

23. Phumat $\mathrm{P}$, Khongkhunthian $\mathrm{S}$, Wanachantararak $\mathrm{P}$, Okonogi S (2018) Effects of Piper betle fractionated extracts on inhibition of Streptococcus mutans and Streptococcus intermedius. Drug Discov Ther 12(3): 133141.

24. Shafiei Z, Shuhairi NN, Md Fazly Shah Yap N, Harry Sibungkil CA, Latip J (2012) Antibacterial Activity of Myristica fragrans against Oral Pathogens. Evid Based Complement Alternat Med 2012: 7.

25. Cai L, Wu CD (1996) Compounds from Syzygium aromaticum possessing growth inhibitory activity against oral pathogens. J Nat Prod 59(10): 987-900.

26. Aneja KR, Joshi R (2009) Antimicrobial Activity of Amomum subulatum and Elettaria cardamomum Against Dental Caries Causing Microorganisms. Ethnobotanical Leaflets 13: 840-849.

27. Hada LS, Kakiuchi N, Hattori M, Namba T (1989) Identification of antibacterial principles against Streptococcus mutans and inhibitory principles against glucosyltransferase from the seed of Areca catechu L. Phytotherapy Research 3(4): 140-144.

28. Galvão LCdC, Furletti VF, Bersan SMF, da Cunha MG, Ruiz ALTG, etal. (2012) Antimicrobial Activity of Essential Oils against Streptococcus mutans and their Antiproliferative Effects. Evid Based Complement Alternat Med 2012: 751435.

29. Hertiani T, Pratiwi S, Duma Kencana Irianto I, Febriana A (2010) Kaempferia galanga L. Rhizome As a Potential Dental Plaque Preventive Agent. 1(1). 